Original Article

\title{
The Effect of Drain vs, no Drain on Straight Leg raising in post Total Knee Replacement Patients
}

\author{
Raza Askari, Pervaiz M. Hashmi, Sheikh Naeem-ul-Haq, Syed Itaat Hussain Zaidi
}

\begin{abstract}
OBJECTIVE: To compare the use of drains vs. no drains in post TKR patients on the basis of mean days to achieve first straight leg raise.

METHODOLOGY: This Cohort Observational Study was carried out at section of Orthopaedic, Dept of Surgery, Aga Khan University Karachi. A total of 94 patients meeting the selection criteria and giving informed consent were included in the study. Inclusion criteria: Patient having bilateral knee joint osteoarthritis grade 4. Exclusion criteria: Septic knee, any infection elsewhere in the body, patients undergoing total knee replacement due to any other cause like rheumatoid arthritis, post traumatic arthritis etc, apart from osteoarthritis. Consecutive series was used and were operated by a single orthopedic surgeon with $>5$ years of experience. In the first 47 patients suction drain was used while in the next 47 no drain was used. The assessment of straight leg raising (SLR) was performed by a senior physiotherapist with experience of $>3$ years in orthopedics physiotherapy, twice a day postoperatively, until the patient performed unassisted straight leg rise. The researcher recorded all the demographic and other relevant variables along with the outcome in the Proforma.

RESULTS: The results showed significant difference in SLR, but no difference in knee society score between drain group versus no drain group.

CONCLUSION: We found advantage of using drain in patients with knee replacement surgeries in terms of rehabilitation that is straight leg raising. Based on the study results and discussion of findings with previous literature, it is recommended that multicenter studies with large sample sizes, measuring multiple outcomes should be conducted in future to reach a firm conclusion regarding use of drain or not in post TKR patients.
\end{abstract}

Keywords: Total Knee Replacement, Straight Leg Raising.

This article may be cited as: Askari R, Hashmi PM, Naeem-ul-Haq S, Zaidi SIH. The Effect of Drain vs. no Drain on Straight Leg raising in post Total Knee Replacement Patients. J Liaquat Uni Med Health Sci. 2018;17(03):152-6. doi: 10.22442/jlumhs.181730568

\section{INTRODUCTION}

Total knee arthroplasty (i.e. total knee replacement) is done to relief significant, disabling pain caused by severe arthritis and make the ambulation easy and better ${ }^{1}$. Post operatively physiotherapy is done to achieve these targets. These post-op exercises include active as well as passive range of motions and quards strengthening exercises which are done in patient until discharge and beyond. A physiotherapist supervises this post-op rehabilitation and documents its progress which may vary in different patients as different patients responds differently to same regimes. Patients also differ in pre-operative status of ambulation and strength of quards muscles. Drains are usually removed within 24 to 48 hours, and the patient is encouraged to walk on the second postoperative day. Patient generally tolerates this regimen well, they are advised to continue their physiotherapy at home too after discharge $\mathrm{e}^{1-9}$.

To use or not to use the drains in total knee arthroplasty has always been an unanswered question. Although the evidence does not prove or disproves the decision to use a drain but they are used as per clinical practice of operating surgeons. There are also surgeons who avoid using these. Both present their logic of practice. Drains are thought to reduce the formation of a hematoma by constantly draining the blood accumulating secondary to surgery and hence prevent the incidence of deep infection ${ }^{10-13}$. On the other hand some studies have shown that use of a drain may be of more bad than good with more wound problems in knees. Drain site may cause leakage of hematoma resulting in more changes of dressing. Soakage of dressings also predisposes the patient to infection whether superficial or deep that is prosthetic joint infection (PJI). There may be areas of ecchymosis also. Drains delay mobilization, could get dislodged and complicates nursing ${ }^{14-21}$. Other studies have shown similar findings with regard to blood loss. In these studies they have concluded that even if there is no constant drainage of hematoma after surgery by not having a drain in place there is no 
increase in the incidence of complications. Infection is another outcome which needs to be looked into but no study has established an increase risk of deep infection with drain placement ${ }^{22-28}$.

Need for transfusions post operatively is also a non resolved issue with different studies quoting different outcomes, some increasing and some having equivocal results 25,15 . Hence going through the literature its that none of the studies provides a compelling reason to use drains. In another study other outcomes like blood transfusion requirements, rehabilitation time, and postoperative complications such as hypotension and wound infections were evaluated and nothing significant was found whether drain was used or not. ${ }^{24}$

In spite of these studies there is scarcity of data on the use of drains or no drains in patients undergoing knee replacement surgeries, in particular to the outcome of duration of straight leg raising, both locally and internationally. Authors have evaluated use of drains or not in patients with total knee replacement surgeries focusing on different outcomes. However, straight-leg raising as one of the outcomes has rarely been measured in these studies. The objective of this study is to evaluate the two postoperative interventions (drains versus no drains) in patients undergoing knee replacement surgeries, so that better management strategies can be adopted for the desired target population.

\section{METHODOLOGY}

This Cohort observational study was carried out at Section of Orthopaedics, Department of Surgery, Aga Khan University Hospital, Karachi from January 2014 to June 2014. A total of 94 patients meeting the selection criteria and giving informed consent were included in the study. Inclusion criteria: Patient having bilateral knee joint osteoarthritis grade 4. Exclusion criteria: Septic knee, any infection elsewhere in the body, patients undergoing total knee replacement due to any other cause like rheumatoid arthritis, post traumatic arthritis etc, apart from osteoarthritis. Patients were postoperatively placed with a drain or not in accordance to consecutive series. The assessment of straight leg raising (SLR) was performed by a senior physiotherapist with experience of $>3$ years in orthopaedics physiotherapy, twice a day postoperatively, until the patient performed unassisted straight leg rise. The researcher recorded all the demographic and other relevant variables along with the outcome in the proforma.

Data was entered in SPSS V.17. Categorical variables (Sex, Group) were summarized as frequencies. Continuous variables i.e. age, knee society score and days to achieve first SLR were analyzed as means with standard deviations.

Intervention and control groups were compared for mean days to achieve first SLR with student's t-test. Stratified analysis was done for potential confounders and effect modifiers i.e. age, sex and BMI. $P$ value of less than 0.05 was taken as significant. Knee Society score post stratification t-test was applied.

\section{RESULTS}

A total of 94 patients with total Knee replacement for osteoarthritis were included in this study. These patients were equally divided into two groups each having 47 patients. The overall mean age of these patients was $68.3 \pm 5.3$ years. In drain group the mean age of the patients was $68.8 \pm 5.2$ years while in no drain group the mean age of the patients was $67.7 \pm 5.3$ years. About $32(34 \%)$ patients had age between 63 to 67 years as shown in figure I. There were $55(58.5 \%)$ males and $39(41.5 \%)$ female. In drain group $25(64.1 \%)$ female and in no drain group 33 $(60.0 \%)$ males as shown in table I. The overall mean $\mathrm{BMI}$ of these patients was $33.4 \pm 2.7$. In drain group the mean BMI was $34.1 \pm 2.7$ while in no drain the mean BMI was $32.8 \pm 2.5$. Overall $79(84.0 \%)$ patients were found obese (BMI >30). In drain group $43(91.5 \%)$ patients found obese and in no drain group 36 $(76.6 \%)$ patients found obese as shown in table II.

The overall mean post-operative was obtained as $4.07 \pm 1.2$ days and the overall knee society score was obtained as $32.91 \pm 1.4$ to achieve first SLR.

There was statistical significant difference mean reduction in drain group was observed $(p<0.01)$ as compared with no drain group as shown in table III.

\section{FIGURE I: HISTOGRAM SHOWING THE DISTRIBUTION OF AGE $(n=94)$}

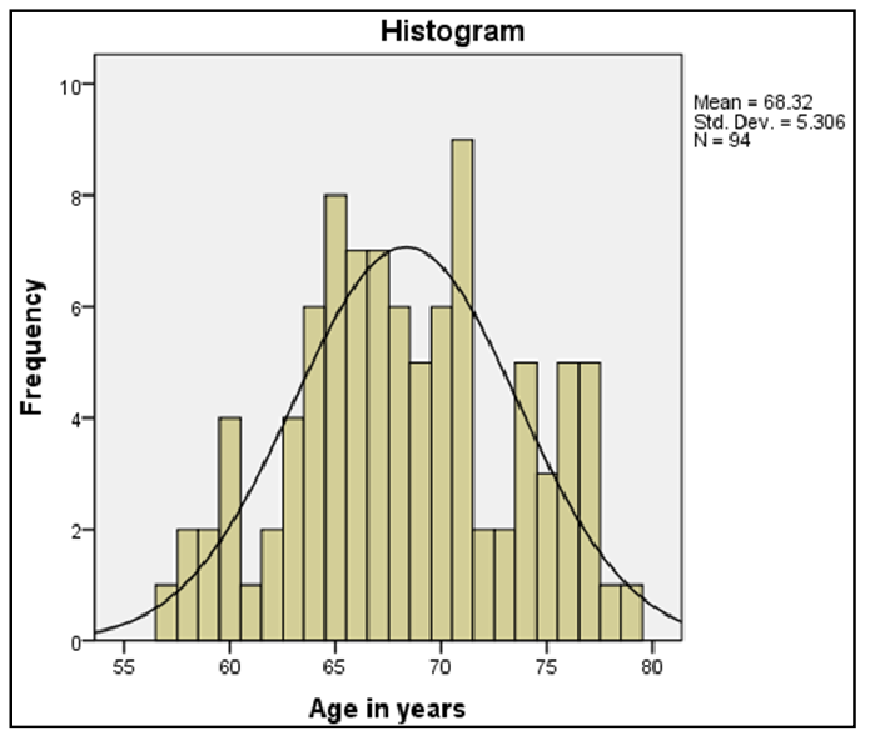


TABLE I: GENDER DISTRIBUTION BY GROUPS $(n=94)$

\begin{tabular}{|l|c|c|c|c|c|c|}
\hline Gender & $\begin{array}{c}\text { Drain } \\
\mathrm{n}=47\end{array}$ & $(\%)$ & $\begin{array}{c}\text { No drain } \\
\mathrm{n}=47\end{array}$ & $(\%)$ & Total & $(\%)$ \\
\hline Male & 22 & 40.1 & 33 & 60.0 & 55 & 58.5 \\
\hline Female & 25 & 64.1 & 14 & 35.9 & 39 & 41.5 \\
\hline Total & 47 & - & 47 & - & 94 & - \\
\hline
\end{tabular}

TABLE II:

DISTRIBUTION OF BODY MASS INDEX $(n=94)$

\begin{tabular}{|c|c|c|c|c|c|c|}
\hline $\mathrm{BMI}$ & $\begin{array}{l}\text { Drain } \\
\text { group } \\
(n=47)\end{array}$ & $(\%)$ & $\begin{array}{c}\text { No drain } \\
\text { group } \\
(n=47)\end{array}$ & (\%) & $\begin{array}{l}\text { Total } \\
(\mathrm{N}=94)\end{array}$ & $(\%)$ \\
\hline $\begin{array}{l}\text { Over weight } \\
(25-30)\end{array}$ & 4 & 8.5 & 11 & 23.4 & 15 & 16.0 \\
\hline Obese $(>30)$ & 43 & 91.5 & 36 & 76.6 & 79 & 84.0 \\
\hline Mean \pm S.D & \multicolumn{2}{|c|}{$34.1 \pm 2.8$} & \multicolumn{2}{|c|}{$32.8 \pm 2.5$} & \multicolumn{2}{|c|}{$33.5 \pm 2.7$} \\
\hline
\end{tabular}

TABLE III: COMPARISON OF POST-OPERATIVE MEAN DAYS AND MEAN KNEE SCORE BY GROUPS $(n=94)$

\begin{tabular}{|l|l|r|c|c|}
\hline & Group & Mean \pm S.D & $\begin{array}{c}\text { Mean } \\
\text { Difference }\end{array}$ & P-value \\
\hline $\begin{array}{l}\text { Post- } \\
\text { Operative } \\
\text { days }\end{array}$ & Drain & $3.66 \pm 1.16$ & -0.83 & 0.001 \\
\cline { 2 - 3 } & No Drain & $4.49 \pm 1.15$ & & \\
\hline \multirow{2}{*}{ Knee score } & Drain & $33.15 \pm 1.33$ & \multirow{2}{*}{0.46} & 0.110 \\
\cline { 2 - 3 } & No Drain & $32.68 \pm 1.47$ & & \\
\hline
\end{tabular}

\section{DISCUSSION}

A Prospective randomized clinical trial was conducted in 92 patients receiving either a single deep closed-suction drain or no drain. Age and gender were comparable in both groups. The results of the above study were that the patients who were placed drain post operatively had significantly greater total blood loss. In these two groups there was no statistical difference in terms of postoperative swelling or pain score. The incidence of pyrexia, ecchymosis, and time at which flexion was regained or the need for manipulation were also the same. In case of the incidence of infection at a minimum of five years after surgery in the two groups there was no statistical difference also. However, there was significant difference in time to straight-leg raising between the groups with less number of days in no drain group ${ }^{23-30}$. Comparing this study to our study, we did not measure these variables except straight-leg raising and knee society scores. The knee scores in our study were comparable in both groups. However, patients in drain group take less time for straight-leg raising than no drain group, as compared to the above study.

Li C $2011^{31}$ conducted a prospective randomized, controlled trial on 100 patients to compare the postoperative use of wound drains with the use of no drains in patients who underwent unilateral primary total knee arthroplasty to determine differences in blood loss, range of motion, wound healing, complications (deep vein thrombosis, wound infection), and need for blood transfusions. They didn't check the end result in straight leg rising postoperatively. The between group difference in total blood loss was significant. Differences in wound infection, incidence of deep vein thrombosis, and range of motion were not statistically significant between groups.

The strengths of our study include, first is a simple objective in measureable terms and predictor and outcome variables with complete objective operational definitions rather than subjective definitions subject to researcher bias. In some studies researchers used subjective assessments which eventually resulted in non standardized application of results. The drain placement in total knee replacement can affect many outcomes which in turn themselves are the outcomes measured in studies. The use of stratification at the data analysis level detects whether the selected variables are themselves confounders so that inferences can be made while discussing results. The caveats include it as an observational study and small sample size. The study uses only few outcome measures and other relevant measures including complications were not measured at this time.

\section{CONCLUSION}

We found advantage of using drain in patients with knee replacement surgeries in terms of rehabilitation that is straight leg raising. Based on the study results and discussion of findings with previous literature, it is recommended that multicenter studies with large sample sizes, measuring multiple outcomes should be conducted in future to reach a firm conclusion regarding use of drain or not in post TKR patients.

\section{REFERENCES}

1. Palmer SH. Total Knee Arthroplasty. Medscape Drug \& Diseases. Available from: http:// emedicine.medscape.com/article/1250275overview.

2. Memtsoudis SG, Sun X, Chiu YL, Stundner O, Liu SS, Banerjee S, et al. Perioperative comparative effectiveness of anesthetic technique in orthopedic patients. Anesthesiology 2013; 118(5): 1046-58. doi: 10.1097/ ALN. 0b013e318286061d.

3. Barone JE. Neuraxial Anesthesia Reduces Joint Surgery Complications. Medscape [Internet]. May 10, 2013. Available from: http:// 
www.medscape.com/ viewarticle/ 804002

4. Artz N, Dixon S, Wylde V, Beswick A, Blom A, Gooberman-Hill R. Physiotherapy provision following discharge after total hip and total knee replacement: A survey of current practice at highvolume NHS hospitals in England and Wales. Musculoskeletal Care 2013 Mar 1; 11(1): 31-8. doi: $10.1002 / \mathrm{msc} .1027$.

5. Madsen M, Larsen K, Madsen IK, Søe H, Hansen TB. Late group-based rehabilitation has no advantages compared with supervised home-exercises after total knee arthroplasty. Dan Med J 2013 Apr; 60(4): A4607.

6. Kadam RV, Yadav S, Chhallani A, Sharma C. Prospective study of clinical and functional outcome of total knee replacement in osteoarthritic knee. Int J Res Orthop 2016; 2(4): 240-4.

7. Wood AM, Keenan AC, Arthur $\mathrm{CH}$, Aitken SA, Walmsley PJ, Brenkel IJ. The functional outcome of total knee replacement in young patients: A 10-year matched case control study. Open J Orthop 2013; 3(2): 128-132.

8. Ranawat CS, Flynn WF Jr, Saddler S, Hansraj $\mathrm{K} K, \quad M$ a $y \mathrm{n}$ a $\mathrm{r} d \quad \mathrm{~d} J$. Long-term results of the total condylar knee arthroplasty. A 15-year survivorship study. Clin Orthop Relat Res. 1993; (286): 94-102.

9. Kim YH, Park JW, Lim HM, Park ES. Cementless and cemented total knee arthroplasty in patients younger than fifty five years. Which is better?. Int Orthop. 2014; 38(2): 297-303. doi: 10.1007/ s00264-013-2243-4

10. Alexander JW, Korelitz J, Alexander NS. Prevention of wound infections. A case for closed suction drainage to remove wound fluids deficient in opsonic proteins. Am J Surg, 1976; 132(1): 5963.

11. Märdian S, Perka C, Matziolis G. Wound drainage in primary knee arthroplasty--a prospective randomized study. Acta Chir Orthop Traumatol Cech. 2013; 80(2): 114-7.

12. Beer KJ, Lombardi AV Jr, Mallory TH, Vaughn BK. The efficacy of suction drains after routine total joint arthroplasty. J Bone Joint Surg AM. 1991; 73(4): 584-7.

13. Cerise EJ, Pierce WA, Diamond DL. Abdominal drains: their role as a source of infection following splenectomy. Ann Surg. 1970; 171(5): 764-9.

14. Chandratreya A, Giannikas K, Livesley P. To drain or not drain: literature versus practice. J R Coll Surg Edinb 1998; 43(6): 404-6.

15. Al-Eyadah Z. Drainage versus nondrainage in primary total knee replacement: a comparative study. Orthopaedic Genius. 2013; 4: 35-7.
16. Lawal YZ, Ogirima MO, Dahiru I, Abubakar K, Ajibade A. On the use of drains in orthopedic and trauma. Niger J Clin Pract. 2014;17(3):366-9.

17. Jepsen OB, Larsen SO, Thomsen VF. Post-operative wound sepsis in general surgery. II. An assessment of factors influencing the frequency of wound sepsis. Acta Chir Scand Suppl, 1969; 396: 80-90.

18. Jung WH, Chun CW, Lee JH, Ha JH, Kim JH, Jeong $\mathrm{JH}$. No difference in total blood loss, haemoglobin and haematocrit between continues and intermittent wound drainage after total knee arthroplasty. Knee Surgery, Sports Traumatology, Arthroscopy. 2013; 21(12): 2831-6.

19. Lidwell OM. Sepsis in surgical wounds. Multiple regression analysis applied to records of post-operative hospital sepsis. J Hyg (Lond), 1961; 59:259-70.

20. Magee C, Rodeheaver GT, Golden GT, Fox J, Edgerton MT, Edlich RF. Potentiation of wound infection by surgical drains. Am J Surg, 1976; 131 (5): 547-9.

21. Goes RFA, Silva AF, Lyra FS, Loures FB, Palma IM, Cobra HA, et al. Prospective randomized study after the use of drains in total knee arthroplasty with implant. Rev Bras Ortop. 2013; 48(3): 257-62.

22. Choudhari $P$, Chhabra S, Singh S. Comparative study of cemented hemiarthroplasty with or without close suction drain. Int J Orthop. 2017; 3 (1): 78-80.

23. Nora PF, Vanecko RM, Bransfield JJ. Prophylactic abdominal drains. Arch Surg, 1972; 105:173-6.

24. Suarez JC, McNamara CA, Barksdale LC, Calvo C, Szubski CR, Patel PD. Closed Suction Drainage Has No Benefits in Anterior Hip Arthroplasty: A Prospective, Randomized Trial. J Arthroplasty. 2016; 31(9):1954-8. doi: 10.1016/ j.arth.2016.02.048.

25. Koyano G, Jinno T, Koga D, Hoshino C, Muneta $T$, Okawa $A$, et al. Is Closed suction drainage effective in early recovery of hip joint function? Comparative evaluation in one-stage bilateral total hip arthroplasty. J Arthroplasty. 2015; 30(1): 74-8. doi:10.1016/j.arth.2014.08.007.

26. Zeng WN, Zhou K, Zhou ZK, Shen B, Yang J, Kang PD, et al. Comparison between Drainage and Non-drainage after Total Hip Arthroplasty in Chinese Subjects. Orthop Surg. 2014; 6(1): 28-32. doi: $10.1111 /$ os.12092.

27. Waugh TR, Stinchfield FE. Suction drainage of orthopaedic wounds. J Bone Joint Surg Am, 1961; 43-A: 939-946.

28. Nanni M, Perna F, Calamelli C, Donati D, Ferrara $\mathrm{O}$, Parlato $\mathrm{A}$, et al. Wound drainages in total hip 
arthroplasty: to use or not to use? Review of the literature on current practice. Musculoskelet Surg. 2013; 97(2): 101-7. doi: 10.1007/s12306-0130270-3

29. Ikpeme IA, Ngim NE, Ilori IU, Oku E, Udosen AM. Prophylactic wound drainage in orthopaedics: a comparative evaluation of closed suction drainage versus no-drainage in a Nigerian teaching hospital. Surg Sci. 2013; 4(05): 277-282.

30. Zhou XD, Li J, Xiong Y, Jiang LF, Li WJ, Wu LD.
Do we really need closed-suction drainage in total hip arthroplasty? A meta-analysis. Int Orthop. 2013; 37(11): 2109-18. doi: 10.1007/s00264-0132053-8.

31. Li C, Nijat A, Askar M. No Clear Advantage to Use of Wound Drains After Unilateral Total Knee Arthroplasty: A Prospective Randomized, Controlled Trial. J Arthroplasty, 2011; 26(4): 51922. doi: 10.1016/j.arth.2010.05.031.

\begin{tabular}{|l|}
\hline AUTHOR AFFILIATION: \\
Dr. Raza Askari (Corresponding Author) \\
Assistant Professor of Orthopaedics \\
Dow International Medical College \\
Dow University of Health Sciences \\
Karachi, Sindh-Pakistan. \\
E-mail: dr_razaaskari@hotmail.com \\
Dr. Pervaiz M. Hashmi \\
Associate Professor of Orthopaedics \\
Aga Khan University Hospital \\
Karachi, Sindh-Pakistan. \\
Dr. Sheikh Naeem-ul-Haq \\
Assistant Professor of Orthopaedics \\
Dow International Medical College \\
Dow University of Health Sciences \\
Karachi, Sindh-Pakistan. \\
Dr. Syed Itaat Hussain Zaidi \\
Assosciate Professor of Orthopaedics \\
Dow International Medical College \\
Dow University of Health Sciences \\
Karachi, Sindh-Pakistan.
\end{tabular}

